\title{
Failure to find a syllabic effect in number naming*
}

\author{
LESLIE HENDERSON \\ University of Guelph, Guelph, Ontario, Canada \\ MAX COLTHEART ${ }^{\dagger}$ \\ University of Reading, Reading, England \\ and \\ DAVID WOODHOUSE \\ University of Guelph, Guelph, Ontario, Canada
}

\begin{abstract}
Experiment I replicated the number-naming studies of Eriksen, Pollack, and Montague (1970) and Klapp (1971) but failed to find consistent evidence of a syllabic effect in naming latencies. Experiment II employed a different set of numbers to investigate sources of confounding in the original stimuli. Again, no syllabic effect was obtained. Both studies provided some evidence that the decades are processed faster.
\end{abstract}

Eriksen, Pollack, and Montague (1970) and Klapp (1971) have reported that the recognition latency for visually presented words and two-digit numbers increases with the number of syllables in the name of the stimulus. Their Ss were required to name the stimuli aloud, and the time to initiate vocalization was measured. The authors conclude that implicit speech is a necessary component of recognition in this task.

In the word recognition study (Eriksen et al, 1970, Experiments I and II), syllabic length is confounded with number of letters in a major way. The number stimuli are free of confounding visual factors. They have another interesting property in that numbers do not have the syllabic structure of their name embodied at the graphemic level. This property has been emphasized by Spoehr and Smith (1973), who report an effect of syllabic length on word recognition thresholds but no effect for two-digit numbers.

\section{EXPERIMENT I}

This experiment is a replication of the two-digit recognition studies by Eriksen et al (1970, Experiment III) and Klapp (1971, Experiment I).

\section{Method}

\section{Apparatus}

The stimuli were the 27 two-digit numbers used by the previous studies and comprising 9 two-, three-, and four-syllable numbers. They consisted of letraset 48-point Helvetica Medium transferred to white cards. When presented in the Scientific Prototype Model GB tachistoscope, they subtended $.6 \mathrm{deg}$ in height and the pair was about $.8 \mathrm{deg}$ wide. Background luminance was $100 \mathrm{~cd} / \mathrm{m}^{2}$ and contrast $90 \%$.

*This research was supported by N.R.C. of Canada, Grant A8263.

$\uparrow$ Reprints may be obtained from Max Coltheart, University of Reading, Reading, England.
The onset of the stimulus field started a Hunter millisecond Klockounter. The S's initial vocalization stopped the clock via an Electro-voice crystal microphone and a Scientific Prototype voice-activated relay. The gain and filters of this device were set so that it invariably triggered to vocalization but never to ambient noise. A switch was wired into parallel timing systems so that closing the switch stopped one clock directly, while the sound of switch closure stopped another clock via the audio relay and microphone. The lag in the audio channel estimated in this way was $19 \pm 1 \mathrm{msec}$.

\section{Procedure}

The Ss were instructed to respond by naming the stimulus as soon as possible after it appeared. Five practice trials were given followed by four runs through the 27 stimuli. For each run, the 27 stimulus cards were shuffled to randomize presentation. Intertrial interval was about $8 \mathrm{sec}$, and a brief rest was given after each run.

Each trial began with the E saying "ready," followed $1 \mathrm{sec}$ later by presentation of the stimulus for a 1-sec duration.

\section{Subjects}

The Ss were 11 students and 4 staff members at the University of Guelph; of these $15 \mathrm{Ss}, 6$ were female.

\section{Results}

Table 1 shows the median reaction time for each $S$ as a function of number of syllables in the numbers. There is no evidence of a consistent syllabic effect. Only 5 of 15 Ss showed a monotonic increase in median RT with number of syllables.

Clearly, there is no difference between latencies to three- and four-syllable numbers. However, two-syllable numbers were faster than three-syllable for $13 \mathrm{Ss}$ and faster than four-syllable for 12 Ss. Both of these differences are significant $(t=4.099$ and 3.233, respectively, $\mathrm{p}<.01$ ).

\section{Discussion}

The failure of the present study to replicate the 
Table 1

Naming Latencies as a Function of Number of Syllables for the Two-Digit Numbers in Experiment I (Median RT in Milliseconds is Given for Each $S$ )

\begin{tabular}{ccccc}
\hline & & \multicolumn{3}{c}{ Number of Syllables } \\
\cline { 2 - 5 } S & Sex & 2 & 3 & 4 \\
\hline VC & F & 564 & 575 & 567 \\
LH & M & 410 & 417 & 402 \\
SH & F & 456 & 444 & 450 \\
JMu & M & 522 & 543 & 540 \\
JW & F & 612 & 617 & 641 \\
JS & M & 558 & 565 & 553 \\
DC & M & 477 & 514 & 484 \\
PH & M & 534 & 527 & 544 \\
DA & M & 468 & 489 & 510 \\
NP & M & 497 & 522 & 544 \\
DW & M & 574 & 609 & 629 \\
JMe & F & 485 & 498 & 501 \\
AS & M & 536 & 549 & 538 \\
SD & F & 462 & 479 & 478 \\
BC & M & 498 & 520 & 516 \\
Mean of Medians & 510 & 525 & 526 \\
Mean of Means & & 518 & 536 & 534 \\
\hline
\end{tabular}

findings of Eriksen et al (1970) and Klapp (1971) cannot be ascribed to any obvious procedural difference. The present Ss underwent fewer sessions, but both previous studies report a lack of interaction with sessions.

A closer examination of Eriksen et al's study suggests, however, that its findings may not be inconsistent with those of this study. ${ }^{1}$ One of Eriksen et al's five Ss was faster over all five sessions for four syllables than for three, thus failing to show evidence of the syllable effect. Furthermore, while Eriksen et al discussed their data in terms of a linear syllabic effect with a slope of $11 \mathrm{msec}$ per syllable, the overall differences which they obtained were, in fact, $17 \mathrm{msec}$ between two and three syllables and $5 \mathrm{msec}$ between three and four. Given the variability of RT, it may be doubted whether a $5-\mathrm{sec}$ difference is likely to be significant.

The results of Eriksen et al (1970) and the present study, but not those of Klapp (1971), could be reconciled with the assumption that the two-syllable numbers are easier to identify than the others, which do not differ from each other. Therefore, it may be significant that the two-syllable numbers in seven out of nine cases were decades. The only other decade used was the three-syllable number "70." The overall mean RT to "70" was $514 \mathrm{msec}$, which when compared to the grand means suggests that "70" behaves like the (two-syllable) decades rather than like the three-syllable numbers. This offers some support to the view that the two-syllable numbers are easier to identify because most are "round numbers."

\section{EXPERIMENT II}

A second experiment was performed with the number-naming task. For this experiment, a new set of number stimuli was chosen which was more systematically balanced across conditions and which, in particular, avoided the confounding of syllables with decades. In addition, the Ss were tested for more sessions to exclude practice as a variable which might differentiate between this and the previous studies.

\section{Method}

\section{Apparatus}

The materials were as in Experiment I save for the actual numbers used. Three sets of numbers were used. A two-syllable teens set comprised $13,14,15,16,18,19$. A two-syllable decades set comprised $30,40,50,60,80,90$. A four-syllable set comprised $73,74,75,76,78,79$. These sets have the property that they all share one digit, with the other digit determined by the specification of tne set (four-syllable numbers necessarily include a 7). In addition, the teens and 70s are well matched in terms of visual features. Finally, the teens differ from the other sets in that it is the second digit which is spoken first when the number is named. Since it is the onset of vocalization which determines RT, it is important thus to preclude a strategy whereby the $\mathrm{S}$ stops the clock by naming the first digit while still processing the second.

\section{Procedure}

The procedure was the same as that of Experiment I save for the following details. A run comprised the 18 stimuli in random order. Six such runs comprised a session. Each $S$ performed four sessions to yield a total of 432 trials.

\section{Subjects}

Ten Ss were selected from the undergraduate population, five of either sex. They were paid $\$ 1.50$ per session for participation.

\section{Results}

Table 2 presents the data, which show no evidence of a syllabic effect.

In this experiment, the decades are apparently faster than the teens but not the 70s. Collapsed over sessions, $t$ tests on the data reveal a significant difference between teens and decades $(t=3.960, p<.01)$ but not between teens and $70 \mathrm{~s}(\mathrm{t}=1.113, \mathrm{p}>.1)$.

\section{DISCUSSION}

The present two experiments failed to detect evidence

Table 2

Mean Naming Latency for Each Condition in Experiment 1

\begin{tabular}{cccc} 
& \multicolumn{2}{c}{ Two Syllables } & Four \\
\cline { 2 - 4 } Session & Teens & Decades & Syllables \\
\hline 1 & 479 & 473 & 485 \\
2 & 461 & 456 & 451 \\
3 & 473 & 459 & 462 \\
4 & 469 & 454 & 456 \\
Mean & 470 & 460 & 463 \\
& Two-Syllable Mean 465 & \\
\hline
\end{tabular}


of a syllabic effect in number recognition. In Experiment I, the overall latencies are identical to those of Klapp (1971) and about $100 \mathrm{msec}$ slower than those of Eriksen et al's (1970) all-male group. The latencies in Experiment II lie halfway between these values. The present studies therefore are inconsistent with the strong assertion that a syllable-dependent implicit-speech process is a necessary stage in the recognition of graphemes.

Eriksen et al (1970) estimated the slope of their syllabic effect as about $11 \mathrm{msec} / \mathrm{syllable}$ (though, as we have observed, there is little reason to accept a linear description of their data). Klapp (1971) obtained a slope of $16.5 \mathrm{msec} / \mathrm{syllable}$. If we extrapolate these values to the zero intercept, then we find a residual 395 and $486 \mathrm{msec}$ of latency unaccounted for by syllabic processes. Klapp also includes a baseline condition in which the $S$ is forewarned of the stimulus identity. This yields a simple detection RT in which the stimulus name is used as a response, thus eliminating the visual discrimination component. The baseline value obtained is $393 \mathrm{msec}$. This leaves almost $100 \mathrm{msec}$ of visual processing time unaccounted for by syllable-dependent processes.

The foregoing analysis suggests that even when a syllable effect can be postulated, it accounts for a very small proportion of stimulus processing time. This conclusion is strengthened by the results of Klapp's (1971) same-different (S/D) experiment with the numbers. This experiment yielded the same slope for the syllabic effect as did number naming. This coincidence seems surprising since the $S / D$ experiment required the processing of twice the number of stimuli, and therefore syllables. This time subtracting the baseline estimate yields about $320 \mathrm{msec}$ of visual processing time, of which syllable-dependent processes only account for $17 \mathrm{msec} / \mathrm{syllable}$.

In conclusion, Spoehr and Smith's (1973) failure to find a syllabic effect in number-recognition thresholds and the present failure to replicate the effect for number-naming latencies, taken in conjunction with the lack of robustness of the effect in Eriksen et al (1970) and the small proportion of recognition time attributable to the effect in Klapp (1971), do not encourage the view that a syllable-dependent implicit-speech process plays a fundamental role in recognition of symbolic material.

\section{REFERENCES}

Eriksen, C. W., Pollack, M. D., \& Montague, W. E. Implicit speech: Mechanism in perceptual encoding? Journal of Experimental Psychology, 1970, 84, 502-507.

Klapp, S. Implicit speech inferred from response latencies in same-different decisions. Journal of Experimental Psychology, $1971,91,262-267$

Spoehr, K. T., \& Smith, E. E. The role of syllables in perceptual processing. Cognitive Psychology, 1973, in press.

\section{NOTE}

1. We are grateful to Dr. Eriksen for providing a breakdown of some of his data.

(Received for publication February 25, 1973; accepted March 3, 1973.) 